\title{
Optic neuropathy in a patient with COVID-19 infection
}

\author{
Patricia Rodrigo-Armenteros ${ }^{1}$. Juan María Uterga-Valiente ${ }^{1}$ Juncal Zabala-Del-Arco ${ }^{2}$ Silvia Taramundi-Argüeso ${ }^{3}$. \\ Lander Antón-Méndez ${ }^{4}$. Juan José Gómez-Muga ${ }^{4}$ Juan Carlos Garcia-Monco ${ }^{1}$ (1)
}

Received: 24 December 2020 / Accepted: 11 January 2021 / Published online: 2 February 2021

(c) Belgian Neurological Society 2021

\section{Introduction}

COVID-19 has been associated with a variety of neurological disorders whose type and frequency are being defined, and include anosmia/ageusia, dizziness, confusion, agitation, headache and stroke [1]. Cranial neuropathies have been occasionally reported, mainly in the form of smell and taste dysfunction, oculomotor paresis, and facial palsy [2]. Peripheral neuropathies have also been described [3]. The optic nerve is not usually involved in SARS-CoV-2 infection.

We here report a case of unilateral optic neuropathy in a patient with a severe pulmonary and encephalopathic presentation of COVID-19.

\section{Case report}

A 62-year-old male, with left eye amblyopia since childhood was admitted in March 2020 for an 8-day history of fever and upper respiratory tract symptoms. Nasopharyngeal reverse transcriptase polymerase chain reaction (RT-PCR) for SARS-CoV-2 was positive and he had hypoxemia and a bilateral interstitial pneumonia. He received hydroxychloroquine (200 mg twice-daily) for 7 days and Lopinavir-Ritonavir

Juan Carlos Garcia-Monco

hospit05@sarenet.es

1 Department of Neurology, Osakidetza Basque Health Service, Basurto University Hospital, 48013 Bilbao, Vizcaya, Spain

2 Department of Internal Medicine, Osakidetza Basque Health Service, Basurto University Hospital, 48013 Bilbao, Vizcaya, Spain

3 Department of Neurophysiology, Osakidetza Basque Health Service, Basurto University Hospital, 48013 Bilbao, Vizcaya, Spain

4 Department of Radiology, Osakidetza Basque Health Service, Basurto University Hospital, 48013 Bilbao, Vizcaya, Spain
(200 mg/50 mg twice-daily) for 15 days. He developed a severe respiratory distress syndrome and was treated with dexamethasone (20 mg daily for 5 days) and tocilizumab (600 mg) with progressive improvement but developed an encephalopathy secondary to nonconvulsive status epilepticus that has been described elsewhere[4]. Blood tests showed an intense systemic inflammatory response with c-reactive protein of $309 \mathrm{mg} / \mathrm{L}$ (normal, $<10 \mathrm{mg} / \mathrm{L}$ ), lactic dehydrogenase $613 \mathrm{U} / \mathrm{L}(<280 \mathrm{U} / \mathrm{L})$, ferritin $5700 \mathrm{ng} / \mathrm{mL}$ ( $<300 \mathrm{ng} / \mathrm{mL})$, and D-dimer $9550 \mathrm{ng} / \mathrm{mL}(<250 \mathrm{ng} / \mathrm{mL})$. Aquaporin-4 and myelin-oligodendrocyte protein (MOG) antibodies were negative.

A lumbar puncture showed normal CSF opening pressure and biochemistry values. RT-PCR for SARS-CoV-2 in the CSF was negative.

Cranial MRI on day 21 showed focal leptomeningeal enhancement in the right parietal peri-Rolandic sulci. There were also unexpected signs of left pre-chiasmatic optic inflammation (Fig. 1).

He did not complain of visual symptoms. Funduscopic examination was normal. Pupillary response to light was normal. Visual evoked potential latency was normal in the right eye (104 s), but was delayed in the left eye (124.9 s). Electroretinography showed an absent response on the left eye, and a normal one on the right eye; these findings indicate that the left eye was functionally blind.

The patient was discharged on day 21 with a normal neurological exam. Brain MRI on day 45 showed resolution of the meningeal enhancement with persistence of the prechiasmatic optic neuritis image.

Cranial nerve involvement, mainly ocular motor palsies may occur in COVID-19[2], but optic nerve involvement is rare [5]. Bilateral optic neuritis has been reported in association with myelitis in a SARS-CoV-2 patient with serum antiMOG antibodies [6]. However, our patient had unilateral involvement without evidence of disseminated CNS involvement, and was seronegative for MOG and aquaporin-4. A recent report described a COVID-19 patient with posterior optic neuropathy but normal inflammatory markers [7]. 
Fig. 1 Brain MRI findings. Brain MRI on day 21 (left panel). Coronal (a, b) and axial (c, d) contrast-enhanced FLAIR images of a brain MRI. Hyperintensity of the pre-chiasmatic cisternal segment of the left optic nerve (arrows) consistent with optic neuritis, along with focal high-intensity content in right parietal peri-rolandic sulci (arrowheads), as a sign of focal leptomeningitis. Furthermore, a diffuse dural enhancement can be noted, consistent with a recent lumbar puncture. Follow-up brain MRI on day 35 (right panel). Coronal $(\mathbf{a}, \mathbf{b})$ and axial $(\mathbf{c}, \mathbf{d})$ contrast-enhanced FLAIR images of a brain MRI, all of them at the same level as the findings described in Fig. 2. Persistence of mild optic neuritis signs can be noted $(\mathbf{a}, \mathbf{b})$. We can also appreciate the resolution of the dural enhancement, and a normal LCR signal intensity content in peri Rolandic sulci, consistent with disappearance of focal leptomeningitis (c, d)
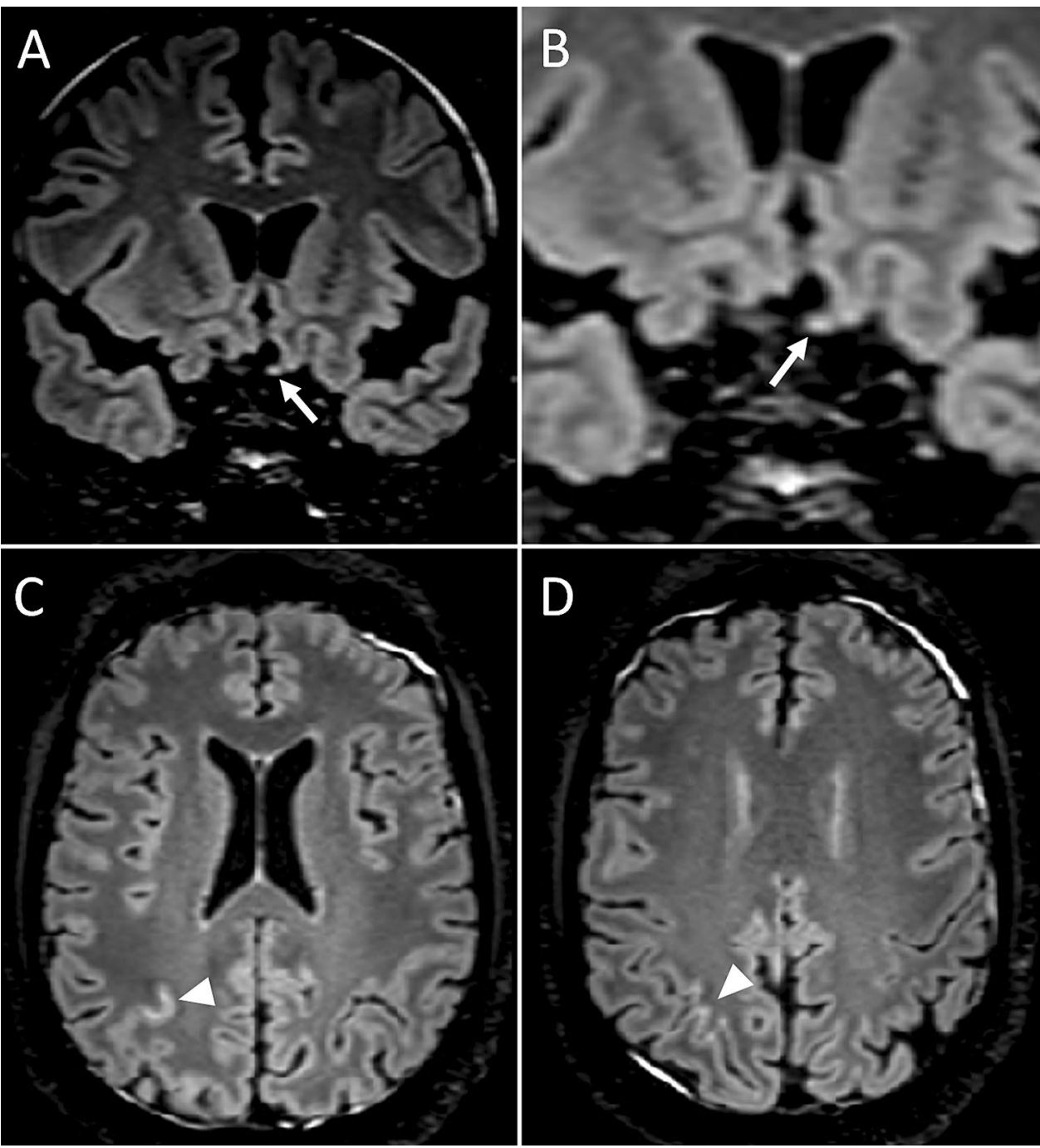

The fact that this patient suffered left eye amblyopia with limited visual acuity since childhood likely explains that he did not complain of optic neuritis symptoms, despite a prolonged P100 latency. This was corroborated by the absence of response in electroretinography.

The mechanism of optic nerve damage in this patient is unclear. Given his normal ophthalmologic exam, a posterior neuropathy in the context of active COVID-19 is more likely. A direct viral damage is not supported, given the normal CSF parameters and the absence of viral RNA in the CSF. A para-infectious mechanism involving the CNS in a similar fashion to that proposed for the delayed occurrence of Miller-Fisher syndrome and Gullain-Barre syndrome in SARS-CoV-2 and in other infections is more likely [2]. In some of these patients the presence of serum anti-GD1b antibodies may have a pathogenic role. Also, an inflammatory systemic reaction associated to SARSCoV-2 infection, as suggested by an increased D-dimer and other inflammatory parameters in our patient, could have resulted in thromboembolic phenomena with occlusion of capillaries feeding the optic nerve.

In conclusion, optic nerve inflammation may be associated with SARS-CoV-2 infection and may go unnoticed in patients with prior amblyopia.

Funding No funding supported this work.

\section{Compliance with ethical standards}

Conflict of interest The authors report no Conflicts to disclosure regarding this manuscript.

Ethical approval This article does not contain any studies with human participants or animals performed by any of the authors.

Informed consent For this type of study informed consent is not required. 


\section{References}

1. Garcia-Monco JC, Cabrera Muras A, Erburu Iriarte M, Rodrigo Armenteros P, Collía Fernández A, Arranz-Martínez J, Kapetanovic S, Lorenzo-García A, Bilbao González A, GomezBeldarrain M (2020) Neurological manifestations in a prospective unselected series of hospitalized COVID-19 patients. Neurol Clin Pract. https://doi.org/10.1212/cpj.0000000000000913

2. Costello F, Dalakas MC (2020) Cranial neuropathies and COVID19: Neurotropism and autoimmunity. Neurology 95(5):195-196. https://doi.org/10.1212/WNL.0000000000009921

3. Dalakas MC (2020) Guillain-Barre syndrome: the first documented COVID-19-triggered autoimmune neurologic disease: more to come with myositis in the offing. Neurol Neuroimmunol Neuroinflamm. https://doi.org/10.1212/NXI.0000000000000781

4. Rodrigo-Armenteros P, María Uterga-Valiente J, Zabala-Del-Arco J, Taramundi-Argüeso S, Erburu-Iriarte M, Antón-Méndez L, José Gómez-Muga J, Garcia-Monco JC (2020) Non-convulsive status epilepticus in a patient with covid-19 infection. Clin Neurophysiol. https://doi.org/10.1016/j.clinph.2020.08.005

5. Tisdale AK, Chwalisz BK (2020) Neuro-ophthalmic manifestations of coronavirus disease 19. Curr Opin Ophthalmol 31(6):489-494. https://doi.org/10.1097/ICU.0000000000000707

6. Zhou S, Jones-Lopez EC, Soneji DJ, Azevedo CJ, Patel VR (2020) Myelin oligodendrocyte glycoprotein antibody-associated optic neuritis and myelitis in COVID-19. J Neuroophthalmol 40(3):398-402. https://doi.org/10.1097/WNO.0000000000001049

7. Selvaraj V, Sacchetti D, Finn A (2013) Dapaah-Afriyie K (2020) acute vision loss in a patient with COVID-19. R I Med J 103(6):37-38

Publisher's Note Springer Nature remains neutral with regard to jurisdictional claims in published maps and institutional affiliations. 